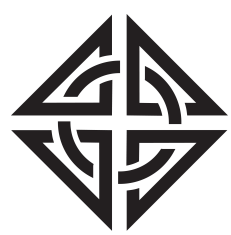

SCIENTIA

I RA N I C A
Sharif University of Technology

Scientia Iranica

Transactions C: Chemistry and Chemical Engineering

http://scientiairanica.sharif.edu

\title{
One-pot synthesis of benzopyranophenazines using graphene oxide dichlorotriazine (GO-DCT) under microwave irradiations
}

\author{
J. Safaei-Ghomi*, M. Tavazo, and H. Shahbazi-Alavi \\ Department of Organic Chemistry, Faculty of Chemistry, University of Kashan, P.O. Box 87317-51167, Iran.
}

Received 18 November 2017; received in revised form 3 March 2018; accepted 21 July 2018

\author{
KEYWORDS \\ Graphene oxide; \\ Pyranophenazines; \\ Nanocatayst; \\ Microwave.
}

\begin{abstract}
An efficient synthesis of benzopyranophenazines is presented by one-pot fourcomponent reaction of hydroxynaphthoquinone, o-phenylenediamine, benzaldehydes, and malononitrile with graphene oxide dichlorotriazine (GO-DCT) as an efficient nanocatalyst under microwave irradiation in ethanol. The catalyst was characterized by Fouriertransform infrared spectroscopy (FT-IR), X-Ray powder Diffraction (XRD), Energy Dispersive Spectroscopy (EDS), Atomic Force Microscopy (AFM), and Scanning Electron Microscopy (SEM). Atom economy, experimental simplicity, wide range of products, low amount of catalyst loading, reusability of the catalyst, excellent yields in short reaction times, and applying the microwave methodology as an efficient and green method are some of the substantial features of this method.
\end{abstract}

(C) 2018 Sharif University of Technology. All rights reserved.

\section{Introduction}

Phenazines have a number of pharmacological activities including anti-tumor [1], antimycobacterial [2], anti-proliferative, [3] antibiotics [4], antifungal [5], and anti-inflammatory [6]. Some phenazines isolated from Streptomyces (a marine bacterium) are described with biological significance (Figure 1) [7-10]. Therefore, seeking efficient and economical methods for the preparation of phenazines through multicomponent reactions (MCRs) is a valuable area of research in organic and medicinal chemistry. Recently, reports have been developed on synthesis of phenazines using $p$-TSA [11], glacial acetic acid [12], 1,4- diazabicyclo[2.2.2] octane (DABCO), [13,14], thiourea-based

\footnotetext{
*. Corresponding author. Tel.: +98-31-55912385; Fax: +98-31-55912397

E-mail address: safaei@kashanu.ac.ir (J. Safaei-Ghomi)
}

organocatalysts [15], caffeine [16], theophylline [17], L-proline [18], 1-butyl-3-methylimidazolium hydroxide $([\mathrm{Bmim}] \mathrm{OH})$ [19], $\mathrm{Et}_{3} \mathrm{~N}$ [20], pyridine [21], and oxalic acid [22]. However, some of the reported methods suffer from drawbacks including long reaction times, generating a large amount of waste, unpleasant reaction conditions, use of toxic, and non-reusable catalyst. Therefore, to avoid these restrictions, the discovery of an efficient and retrievable catalyst with high catalytic activity for the synthesis of benzopyranophenazines is still favored. Recently, Graphen Oxide (GO) has attracted significant interest as the catalyst in organic synthesis [23,24]. Graphene and graphen oxide have large specific surface area, high surface-to-volume ratio, and chemical stability $[25,26]$. The graphene oxide is an effective platform for the construction of functionalized graphene platelets that can potentially confer improved mechanical, thermal, and electronic properties. Both small molecules and polymers have been covalently tethered to graphene oxide's highly reactive oxygen functionalities, or non-covalently at- 


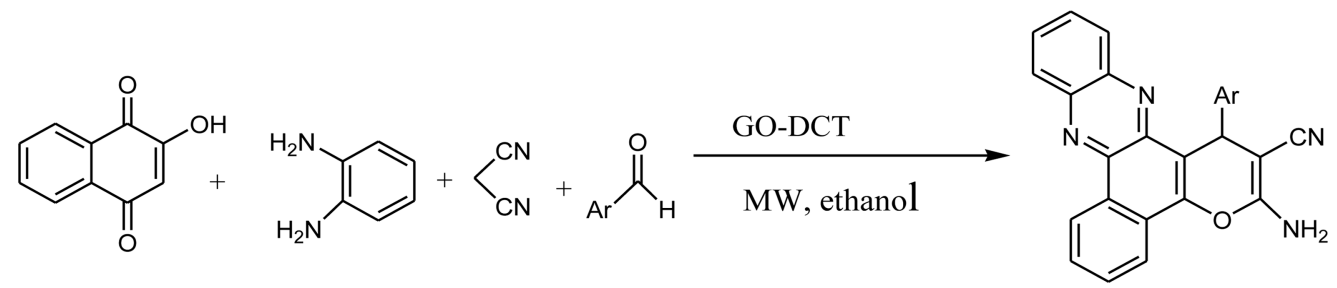

Scheme 1. Synthesis of benzopyranophenazines using graphene oxide dichloro triazine (GO-DCT) under microwave irradiations.

tached on the graphene surfaces, for potential use in sensors, polymer composites, paper-like materials, photovoltaic applications, and drug-delivery systems [2731]. Herein, we wish to report the use of graphene oxide dichloro triazine (GO-DCT) as an efficient catalyst for the preparation of benzopyranophenazines by a multicomponent reaction of hydroxynaphthoquinone, $o$-phenylenediamine, benzaldehydes, and malononitrile under microwave irradiation (Scheme 1).

\section{Experimental section}

\subsection{Chemicals and apparatus}

${ }^{1} \mathrm{H}$ NMR and ${ }^{13} \mathrm{C}$ NMR spectra were recorded on Bruker Avance-400 MHz spectrometer using DMSO$d_{6}$ as solvent. The elemental analyses $(\mathrm{C}, \mathrm{H}, \mathrm{N})$ were obtained from a Carlo ERBA Model EA 1108 analyzer. Fourier transform infrared (FTIR) spectra were recorded on WQF-510, spectrometer 550 Nicolet. The Energy-Dispersive X-ray Spectroscopy (EDS) measurements were performed by SAMX analyzer. The AFM of GO nanosheets were measured using a Scanning Probe Microscope (SPM-9600, Shimadzu). Powder XRay Diffraction (XRD) measurements were carried out on a Philips diffractometer of X'pert Company with monochromatized $\mathrm{Cu} \mathrm{K} \alpha$ radiation $(\lambda=1.54056 \mathrm{~nm})$. SEM images were taken by MIRA3-TESCAN.

\subsubsection{Preparation of graphene oxide dichlorotriazine (GO-DCT)}

At first, GO was prepared from graphite powder through the improved hummers method as starting material [32]. $0.5 \mathrm{~g}$ graphite powder was dispersed into $200 \mathrm{~mL} \mathrm{H}_{2} \mathrm{SO}_{4}(98 \%)$, sonicated for $2 \mathrm{~h}$ at $50^{\circ} \mathrm{C}$, and stirred for $24 \mathrm{~h}$. Then, $10 \mathrm{~g} \mathrm{NaNO}_{3}$ was added into stable dispersion and the mixture of reaction was placed in ice-water bath under stirring for $1 \mathrm{~h} .30 \mathrm{~g}$ $\mathrm{KMnO} 4$ was added slowly and stirred for $24 \mathrm{~h}$. Then, $200 \mathrm{~mL} \mathrm{H}_{2} \mathrm{O}$ and $60 \mathrm{~mL} \mathrm{H}_{2} \mathrm{O}_{2}$ were added into the mixture of reaction. The color of the reaction material was light brown, which was filtrated and washed with water and dried in oven. The obtained GO (1 g) was

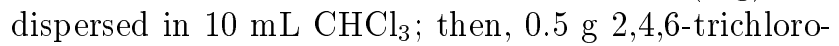
1,3,5-triazine was added and stirred for $24 \mathrm{~h}$ at room temperature. The obtained solution was filtrated and washed with $\mathrm{CHCl}_{3}$ and dried in oven.

\subsubsection{Preparation of benzopyranophenazines}

A mixture of hydroxynaphthoquinone (1 mmol), ophenylenediamine $(1 \mathrm{mmol})$, an aldehydes (1 mmol), malononitrile $(1.5 \mathrm{mmol})$, and graphene oxide dichlorotriazine (GO-DCT) $(8 \mathrm{mg})$ in EtOH $(15 \mathrm{~mL})$ was irradiated inside microwave oven at the power level of $500 \mathrm{~W}$ for the appropriate time. After completion of the reaction (TLC), hot ethanol $(10 \mathrm{~mL})$ was added. The catalyst was insoluble in hot ethanol, and it could be recycled by centrifuging. The solvent was evaporated and a solid was obtained to afford the benzopyranophenazines. The pure products were characterized by comparison of their physical data (melting points, IR, and H NMR) with those of known compounds in the literature.

\subsubsection{Spectral data of products}

3-Amino-1-(4-cyano-phenyl)-1H-benzo[a]pyrano[2,3c]phenazine-2- carbonitrile $(\mathbf{5 h})$ :

Yellow solid, m.p.: $288-290^{\circ} \mathrm{C}$; IR $\left(\mathrm{KBr}, \nu, \mathrm{cm}^{-1}\right)$ : $3322,3176,3045,2831,2182,2139,1644,1622,1584$, $1483,1455,1444,1392,1383,1355,1337,1292,1256$, 1160; ${ }^{1} \mathrm{H}$ NMR (400 MHz, DMSO-d $\left.d_{6}\right)(\delta, \mathrm{ppm}): 5.42$ $(\mathrm{s}, 1 \mathrm{H}, \mathrm{CH}), 7.23\left(\mathrm{~s}, 2 \mathrm{H}, \mathrm{NH}_{2}\right), 7.38(\mathrm{~d}, J=8.0 \mathrm{~Hz}$, $2 \mathrm{H}, \mathrm{Ar}-\mathrm{H}), 7.42$ (d, $J=8.0 \mathrm{~Hz}, 2 \mathrm{H}, \mathrm{Ar}-\mathrm{H}), 7.83-8.08$ (m, 4H, Ar-H), 8.12-8.15 (m, 1H, Ar-H), 8.17-8.22 (m, $1 \mathrm{H}, \mathrm{Ar}-\mathrm{H}), 8.42$ (d, 1H, $J=7.6 \mathrm{~Hz}, \mathrm{Ar}-\mathrm{H}), 9.17(\mathrm{~d}, 1 \mathrm{H}$, $J=7.2 \mathrm{~Hz}, \mathrm{Ar}-\mathrm{H}) ;{ }^{13} \mathrm{C} \mathrm{NMR}\left(100 \mathrm{MHz}, \mathrm{DMSO}-d_{6}\right)$ $(\delta, \mathrm{ppm}): 37.3,57.9,113.8,115.3,118.3,122.1,124.3$, $125.5,126.3,127.8,128.2,128.6,129.0,129.2,130.1$, $130.3,130.6,130.8,139.9,140.1,140.7,141.4,145.6$, 146.5, 159.5; Anal. Calcd. for $\mathrm{C}_{27} \mathrm{H}_{15} \mathrm{~N}_{5} \mathrm{O}$ : C, 76.22; H, 3.55; N, 16.46; Found: C, 76.18; H, 3.43; N, 16.35 .

\section{3-Amino-1-(4-methoxy-phenyl)-1H-}

benzo[a]pyrano[2,3-c]phenazine-2- carbonitrile $(\mathbf{5 m})$ : Yellow solid, m.p.: $268-269^{\circ} \mathrm{C}$; IR (KBr, $\left.\nu, \mathrm{cm}^{-1}\right)$ : 3315, 3174, 3048, 2829, 2180, 1652, 1620, 1585, 1487, $1465,1450,1394,1384,1350,1330,1293,1258,1163$; ${ }^{1} \mathrm{H}$ NMR (400 MHz, DMSO- $\left.d_{6}\right)(\delta, \mathrm{ppm}): 3.84(\mathrm{~s}, 3 \mathrm{H}$, $\left.\mathrm{OCH}_{3}\right), 5.83(\mathrm{~s}, 1 \mathrm{H}, \mathrm{CH}), 6.65(\mathrm{~d}, 2 \mathrm{H}, J=7.6 \mathrm{~Hz}$, Ar-H), $6.90(\mathrm{~d}, 2 \mathrm{H}, J=7.6 \mathrm{~Hz}, \mathrm{Ar}-\mathrm{H}), 7.35$ (s, $\left.2 \mathrm{H}, \mathrm{NH}_{2}\right), 7.85-7.93(\mathrm{~m}, 4 \mathrm{H}, \mathrm{Ar}-\mathrm{H}), 7.98-8.40(\mathrm{~m}$, $3 \mathrm{H}), 9.10(\mathrm{~d}, 1 \mathrm{H}, J=8.0 \mathrm{~Hz}, \mathrm{Ar}-\mathrm{H}) ;{ }^{13} \mathrm{C} \mathrm{NMR}$ $\left(100 \mathrm{MHz}, \mathrm{DMSO}-d_{6}\right)(\delta, \mathrm{ppm}): 37.5,55.2,58.3$, $112.1,115.2,115.5,120.2,120.4,121.4,125.2,127.0$, 


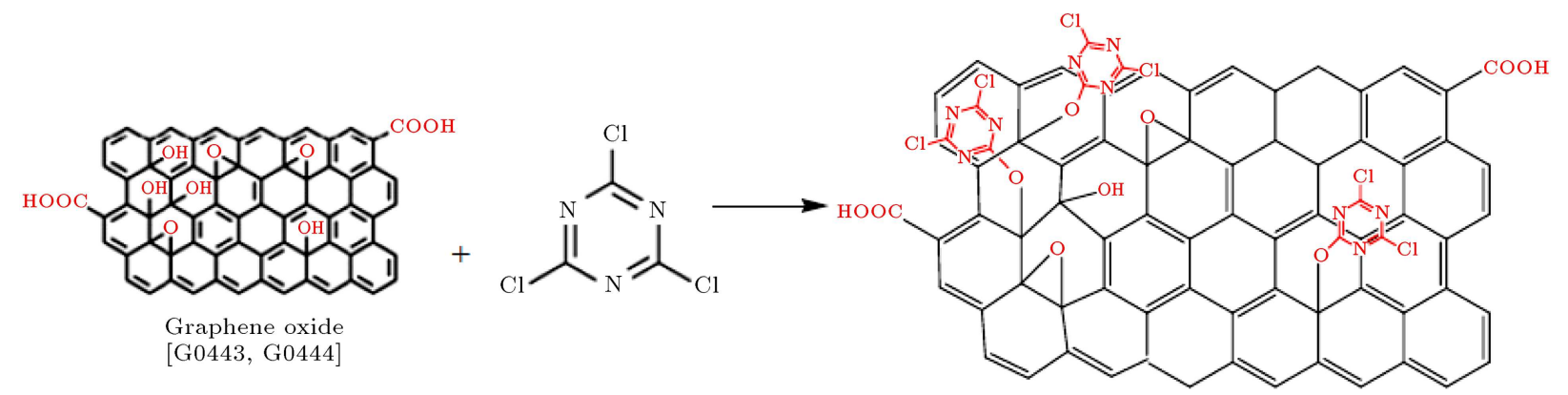

Scheme 2. Preparation routes of graphene oxide dichloro triazine (GO-DCT).

$129.1,129.3,129.7,130.1,130.5,130.8,130.9,140.3$ 141.2, 141.9, 146.4, 147.3, 159.4, 160.5; Anal. Calcd. for $\mathrm{C}_{27} \mathrm{H}_{18} \mathrm{~N}_{4} \mathrm{O}_{2}$ : C, 75.34; H, 4.21; N, 13.02; Found C, $75.25 ; \mathrm{H}, 4.15 ; \mathrm{N}, 12.93$.

\section{Results and discussion}

The process for the preparation of graphene oxide dichlorotriazine (GO-DCT) catalyst is schematically described in Scheme 2. Graphene Oxide nanosheets (GO) were prepared using a modified Hummer's method and subsequently functionalized with dichlorotriazine.

XRD patterns of graphene oxide dichlorotriazine (GO-DCT) are shown in Figure 1. The characteristic peaks in the spectrum are in agreement with the standard XRD pattern of functionalized-graphene oxides [29-33].

The morphology of graphene oxide dichlorotriazine was investigated by Scanning Electron Microscopy (SEM) as shown in Figure 2. The SEM image of graphene oxide dichlorotriazine nanoplatelets showed crumpled thin layers with wrinkles and folds on the surface of GO.

The FT-IR spectra of graphene oxide and graphene oxide dichlorotriazine are shown in Figure 3. The FT-IR spectrum of GO demonstrates the characteristic oxygen-containing groups. The character-

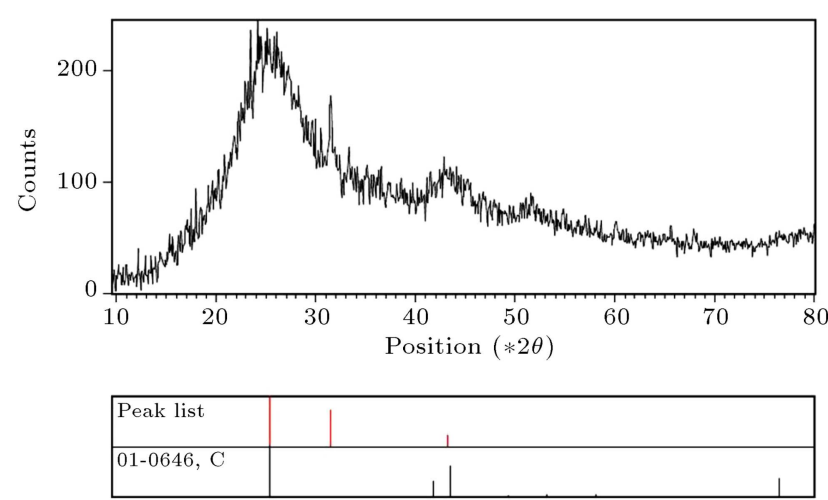

Figure 1. The XRD pattern of graphene oxide dichlorotriazine (GO-DCT).

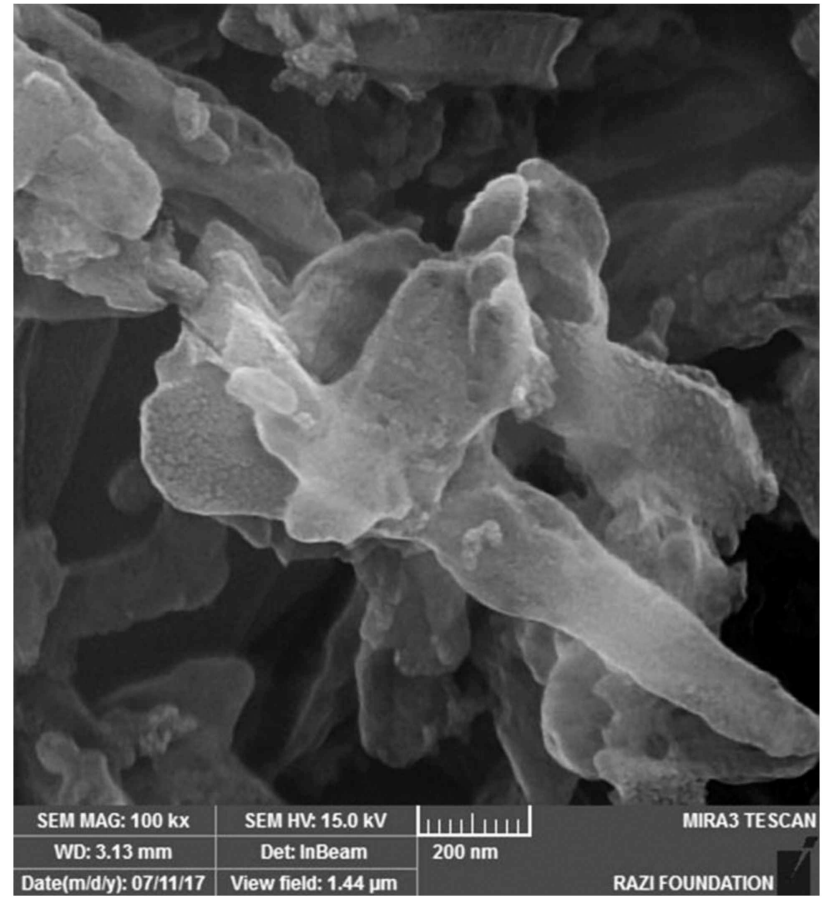

Figure 2. SEM image of graphene oxide dichlorotriazine (GO-DCT).

istic peaks at $3443 \mathrm{~cm}^{-1}$ (O-H stretching vibration), $1704 \mathrm{~cm}^{-1}\left(\mathrm{C}=\mathrm{O}\right.$ stretching vibration), and $1126 \mathrm{~cm}^{-1}$ (C-O-C stretching vibration) appear in the spectrum of GO [33]. The peak at approximately $1659 \mathrm{~cm}^{-1}$ is attributed to $\mathrm{C}=\mathrm{C}$ double bonds. Figure $3(\mathrm{~b})$ shows the FT-IR spectrum of graphene oxide dichlorotriazine. The intense peaks appearing at around 619,1123 , and $1580 \mathrm{~cm}^{-1}$ are attributed to stretching vibrations of C$\mathrm{Cl}, \mathrm{C}-\mathrm{O}$, and $\mathrm{C}=\mathrm{N}$ bonds. These basic characteristic peaks verify that dichlorotriazine is coated on the surface of graphene oxide.

Figure 4 shows the EDS spectra of graphene oxide dichlorotriazine. The presence of elements such as carbon, oxygen, nitrogen, and chlor was confirmed by EDS spectroscopy.

Atomic Force Microscopy (AFM) was utilized to observe the morphology of GO nanosheets and measure their thickness. The AFM images of GO and graphene oxide dichlorotriazine easily confirm the wrinkled two- 


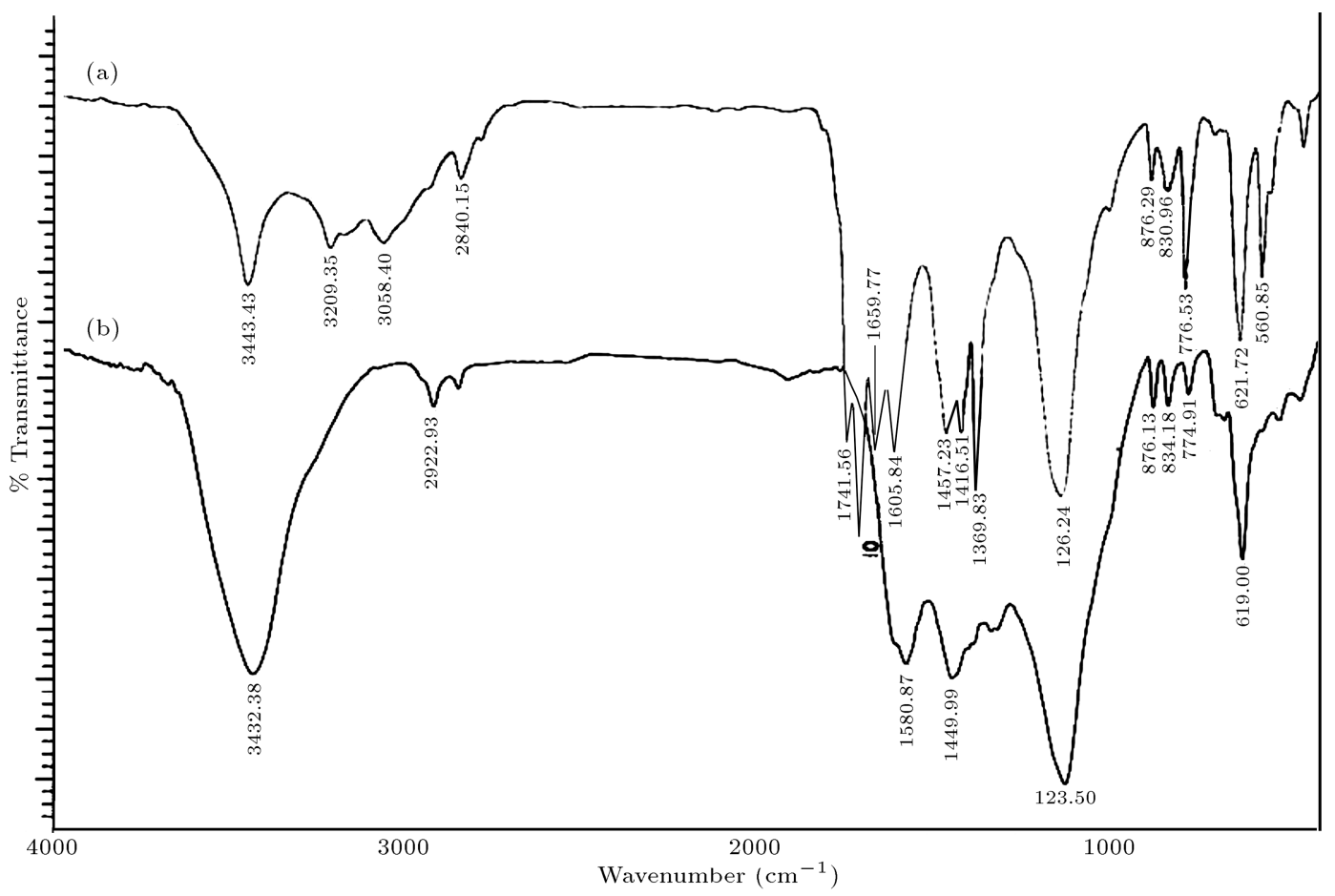

Figure 3. FT- IR spectrum of graphene oxide (a) and graphene oxide dichlorotriazine (b).

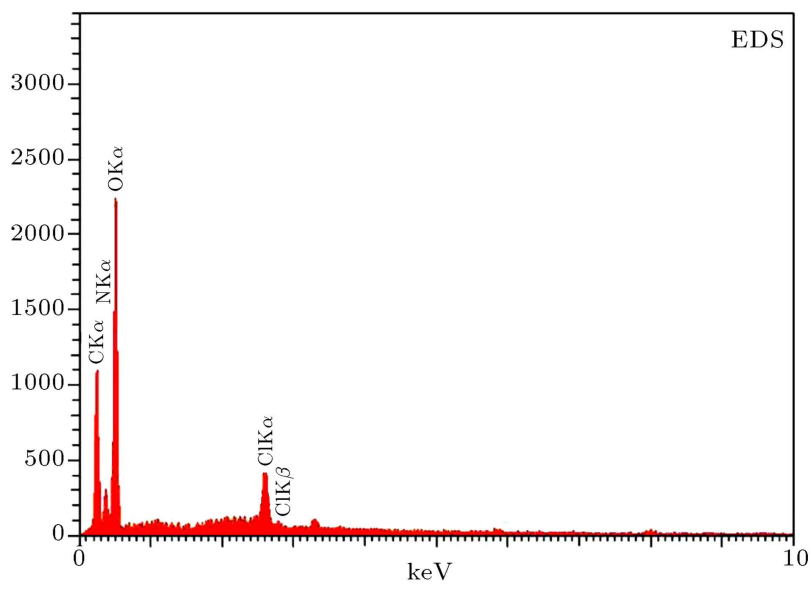

Figure 4. EDS spectrum of graphene oxide dichlorotriazine (GO-DCT).

dimensional characteristic of the GO nanosheets. The images show that the thickness of GO is approximately 0.9 to $1.5 \mathrm{~nm}$, corresponding to structures with one to two layers (Figure 5(a) and (b)).

Initially, we focused on systematic evaluation of different catalysts for the model reaction of hydroxynaphthoquinone, o-phenylenediamine, 4chlorobenzaldehyde, and malononitrile under different conditions. To obtain the ideal reaction conditions for the synthesis of compound $\mathbf{5 b}$, we studied some other catalysts and solvents, which are shown in Table 1. Screening of diverse catalysts such as $\mathrm{NiCl}_{2}$, imidazole, $\mathrm{ZrOCl}_{2}, P$-TSA, GO, and GO-DCT revealed GO-DCT as the most effective catalyst to perform this reaction under microwave irradiation in ethanol. In further studies on the catalyst loading, we recognized that yield of compound $\mathbf{5 b}$ remained almost the same when $8 \mathrm{mg}$ of GO-DCT was used (Table 1 ). Use of lower catalyst loading $(6 \mathrm{mg})$ afforded $\mathbf{5 b}$ in $89 \%$ yield. The results illustrated that the microwave certainly affected the reaction system. It could reduce the reaction time and increase the yield of the products (Table 2). When the reaction was carried out under reflux conditions, it gave low yields of products and took longer reaction times, while the same reaction was carried out under microwave irradiation to give excellent yields of products in short reaction times. Therefore, it was observed that the reaction in the presence of $8 \mathrm{mg}$ GO-DCT and under microwave irradiation gave the best result as the obtained product was $96 \%$ isolated yield during 10 minutes.

The results show that the present catalytic method is extensible to a wide diversity of substrates to create a variety-oriented library of benzopyranophenazines. From the above observation, it is important to mention that electron-withdrawing groups increase the rate of reaction and give better yields than electron-donating groups (Table 2).

We investigated reusability of the GO-DCT as catalyst for the preparation of product $\mathbf{5 b}$ and it was found that product yields were reduced to a small extent in each reuse (run 1,96\%; run 2, 96\%; run $3,96 \%$; run $4,95 \%$; run $5,95 \%$, run $6,94 \%$ ). After completion of the reaction, the nanocatalyst was easily separated using centrifuging. The catalyst was washed 
Table 1. Optimization of reaction conditions using different catalysts under different conditions ${ }^{\mathrm{a}}$.

\begin{tabular}{|c|c|c|c|c|}
\hline Entry & Solvent (conditions) & Catalyst & Time (min) & Yield $(\%)^{\mathrm{c}}$ \\
\hline 1 & EtOH (reflux) & No catalyst & 400 & Trace \\
\hline 2 & EtOH (reflux) & $\mathrm{NiCl}_{2}(5 \mathrm{~mol} \%)$ & 400 & 42 \\
\hline 3 & EtOH (reflux) & $\mathrm{ZrOCl}_{2}(5 \mathrm{~mol} \%)$ & 500 & 45 \\
\hline 4 & EtOH (reflux) & imidazole (7 mol\%) & 400 & 35 \\
\hline 5 & EtOH (reflux) & $p$-TSA ( 8 mol $\%)$ & 250 & 53 \\
\hline 6 & EtOH (reflux) & $\mathrm{GO}(15 \mathrm{mg})$ & 250 & 57 \\
\hline 7 & $\mathrm{H}_{2} \mathrm{O}$ (reflux) & GO-DCT (15 mg) & 150 & 46 \\
\hline 8 & DMF (reflux) & GO-DCT (15 mg) & 150 & 55 \\
\hline 9 & $\mathrm{CH}_{3} \mathrm{CN}$ (reflux) & GO-DCT (15 mg) & 150 & 64 \\
\hline 10 & EtOH (reflux) & GO-DCT (15 mg) & 150 & 75 \\
\hline 11 & $\mathrm{H}_{2} \mathrm{O}(\mathrm{MWI}: 400 \mathrm{~W})^{\mathrm{b}}$ & GO-DCT (10 mg) & 15 & 56 \\
\hline 12 & DMF (MWI: 400 W) & GO-DCT (10 mg) & 15 & 68 \\
\hline 13 & $\mathrm{CH}_{3} \mathrm{CN}$ (MWI: $400 \mathrm{~W}$ ) & GO-DCT (10 mg) & 15 & 79 \\
\hline 14 & EtOH (MWI: 300 W) & GO-DCT (8 mg) & 10 & 86 \\
\hline 15 & EtOH (MWI: 400 W) & GO-DCT (8 mg) & 10 & 96 \\
\hline 16 & EtOH (MWI: 500 W) & GO-DCT $(8 \mathrm{mg})$ & 10 & 96 \\
\hline 17 & EtOH (MWI: 400 W) & GO-DCT (6 mg) & 10 & 89 \\
\hline 18 & EtOH (MWI: 400 W) & GO-DCT (10 mg) & 10 & 96 \\
\hline 19 & EtOH (MWI: 400 W) & GO $(12 \mathrm{mg})$ & 10 & 81 \\
\hline \multicolumn{5}{|c|}{$\begin{array}{l}\text { O-phenylenediamine }(1 \mathrm{mmol}) \text {, 4-chlorobenzaldehyde }(1 \mathrm{mmol}) \text {, } \\
\text { and malononitrile }(1.5 \mathrm{mmol}) \text { as a model reaction; }\end{array}$} \\
\hline Microwa & irradiation; & & & \\
\hline
\end{tabular}

Table 2. Synthesis of benzopyranophenazine derivatives.

\begin{tabular}{|c|c|c|c|c|c|}
\hline Entry & $\boldsymbol{R}$ & Product & Time (min) & Yield $(\%)^{a}$ & $\mathrm{~m} \cdot \mathrm{p} /{ }^{\circ} \mathrm{C}$ found (reported) \\
\hline 1 & $\mathrm{H}$ & $5 \mathbf{a}$ & 10 & 92 & $297-300(298-300)[34]$ \\
\hline 2 & $4-\mathrm{Cl}$ & $5 \mathrm{~b}$ & 10 & 96 & $290-292(288-290)[34]$ \\
\hline 3 & $2-\mathrm{Cl}$ & $5 c$ & 10 & 93 & 299-302 (301-303) [34] \\
\hline 4 & $4-\mathrm{Br}$ & $5 d$ & 10 & 97 & $282-284(283-285)[34]$ \\
\hline 5 & $4-\mathrm{F}$ & $5 \mathrm{e}$ & 10 & 98 & $273-276(274-276)[34]$ \\
\hline 6 & $3-\mathrm{NO}_{2}$ & $5 f$ & 10 & 93 & $277-281(278-279)[34]$ \\
\hline 7 & $4-\mathrm{NO}_{2}$ & $5 \mathrm{~g}$ & 10 & 98 & $280-282(281-283)[34]$ \\
\hline 8 & $4-\mathrm{CN}$ & $5 \mathrm{~h}$ & 10 & 91 & $288-290$ \\
\hline 9 & $4-\mathrm{N}(\mathrm{Me})_{2}$ & $5 \mathrm{i}$ & 15 & 84 & $261-263(261-263)[34]$ \\
\hline 10 & $4-\mathrm{Me}$ & $5 \mathrm{j}$ & 15 & 86 & $293-295(293-294)[34]$ \\
\hline 11 & $2-\mathrm{OMe}$ & $5 \mathrm{k}$ & 15 & 82 & $268-270(270-272)[34]$ \\
\hline 12 & $3-\mathrm{OMe}$ & 51 & 15 & 84 & $239-241(240-242)$ [34] \\
\hline 13 & 4-OMe & $5 \mathrm{~m}$ & 15 & 82 & $268-269$ \\
\hline 14 & 2,4-dichloro & $5 n$ & 10 & 97 & 306-309 (308-310) [34] \\
\hline
\end{tabular}

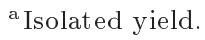



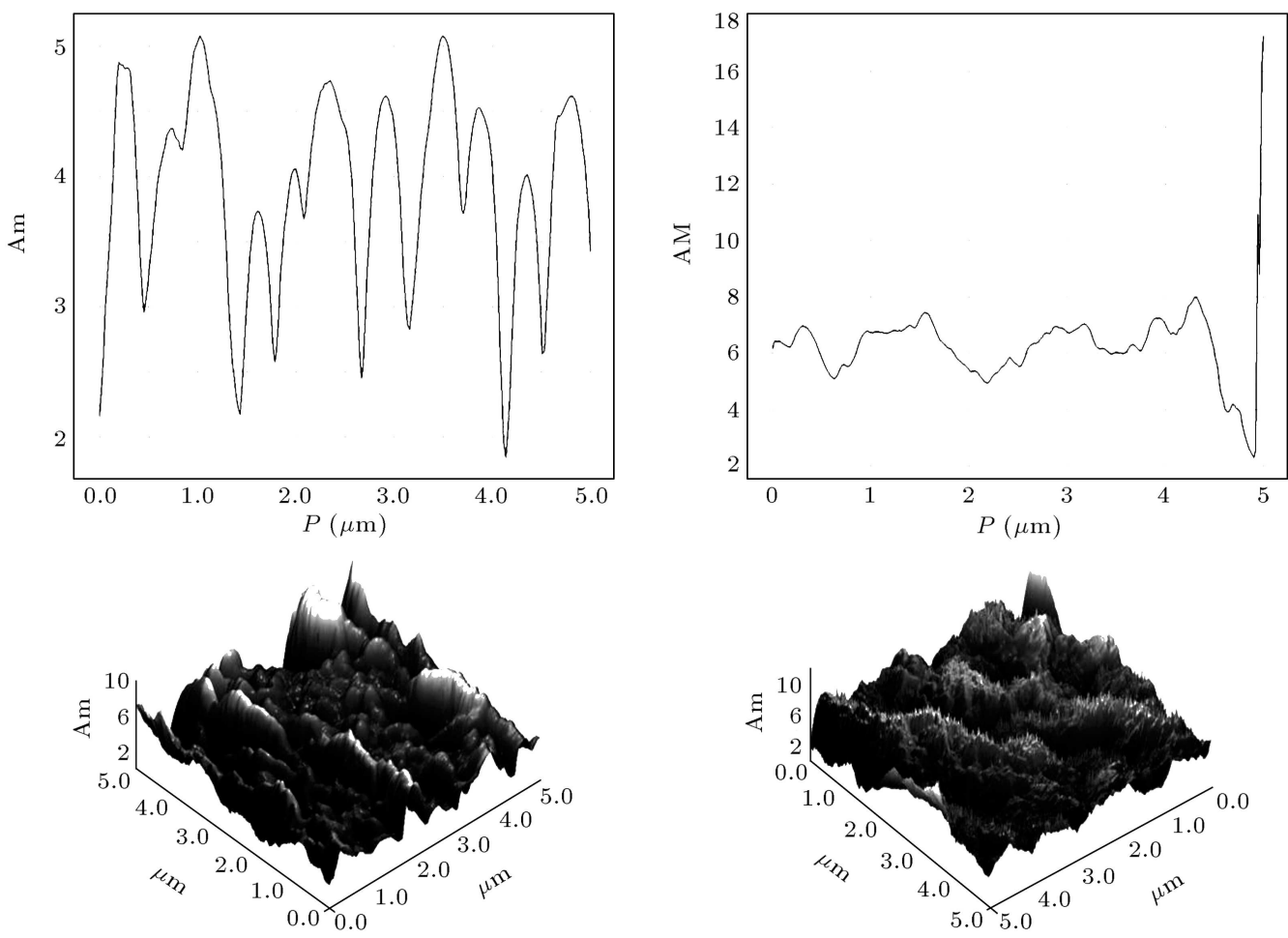

(a)

(b)

Figure 5. AFM of graphene oxide (a) and graphene oxide dichlorotriazine (b).

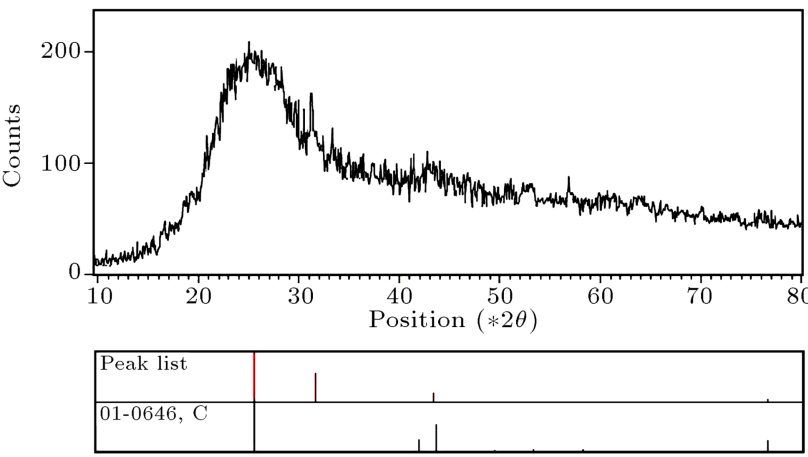

Figure 6. XRD patterns of graphene oxide dichlorotriazine catalyst after 5 runs.

four times with ethanol and dried at room temperature for $24 \mathrm{~h}$

In order to investigate the structural change of catalyst, the XRD pattern of recovered catalyst was provided (Figure 6). The result showed that there was no structural change after the reaction.

A proposed mechanism for the synthesis of benzopyranophenazines using GO-DCT is shown in Scheme 3:

(i) The initial condensation of hydroxynaphthoquinone with $o$-phenylenediamine afforded intermediate $\mathbf{I}$;

(ii) Knoevenagel condensation of malononitrile and benzaldehydes formed intermediate II; (iii) The Michael addition of intermediate $\mathbf{I}$ to intermediate II formed intermediate III, which in the subsequent cyclization and tautomerism afforded the corresponding products.

In this mechanism, the surface atoms of GO-DCT behaved as the centers where chemical reactions could be catalytically stimulated. The proposed mechanism has been supported in the literature $[15,19,34]$. Therefore, the superior performance of GO-DCT can mainly be attributed to many active sites such as $-\mathrm{OH},-\mathrm{COOH}$, and triazines groups.

\section{Conclusions}

We developed a straightway and efficient method for the preparation of benzopyranophenazines using GODCT as an efficient catalyst under microwave irradiation. The method offers several advantages including rapid assembly of medicinally privileged heterocyclic molecules, use of easily available substrates, high yields, shorter reaction times, reusability of the catalyst, low amount of catalyst, and use of microwave irradiation as a valuable and powerful technology.

\section{Acknowledgement}

The authors are grateful to University of Kashan for supporting this work. 


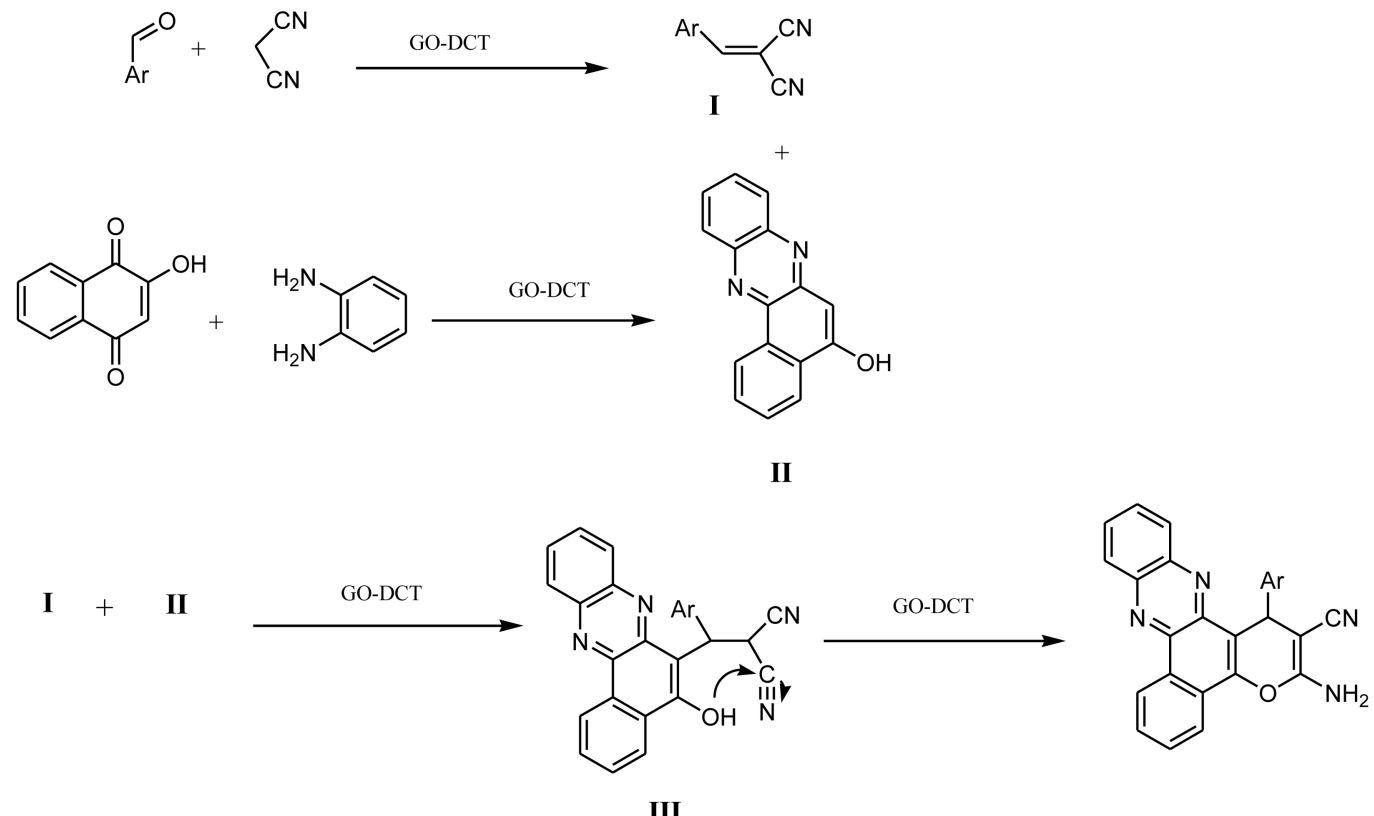

Scheme 3. A proposed mechanism for the synthesis of benzopyranophenazines.

\section{References}

1. Tarui, M., Doi, M., Ishida, T., Inoue, M., Nakaike, S., and Kitamurat, K. "DNA-binding characterization of a novel anti-tumour benzo [a] phenazine derivative NC182: spectroscopic and viscometric studies", Biochem. J., 304, pp. 271-279 (1994). DOI: 10.1042/bj3040271

2. Jardim, G.A.M., Cruz, E.H.G., Valença, W.O., Resende, J.M., Rodrigues, B.L., Ramos, D.F., Oliveira, R.N., Silva, P.E.A., and Junior, E.N.S. "On the search for potential antimycobacterial drugs: synthesis of naphthoquinoidal, phenazinic and 1,2,3-triazolic compounds and evaluation against mycobacterium tuberculosis", J. Braz. Chem. Soc., 26, pp. 1013-1027 (2015). DOI: $10.5935 / 0103-5053.20150067$

3. Terenzi, A., Tomasello, L., Spinello, A., Bruno, G., Giordano, C., and Barone, G. "(Dipyrido[3,2a:2', $3^{\prime}$-c] phenazine)(glycinato)copper(II) perchlorate: A novel DNA-intercalator with anti-proliferative activity against thyroid cancer cell lines", J. Inorg. Biochem., 117, pp. 103-110 (2012). DOI: 10.1016/j.jinorgbio.2012.08.011

4. Price-Whelan, A., Dietrich, L.E.P., and Newman, D.K. "Rethinking 'secondary' metabolism: physiological roles for phenazine antibiotics", Nat. Chem. Boil., 2, pp. $71-78$ (2006). DOI: $10.1038 /$ nchembio764

5. Park, J.Y., Oh, S.A., Anderson, A.J., Neiswender, J., Kim, J.C., and Kim, Y.C. "Production of the antifungal compounds phenazine and pyrrolnitrin from Pseudomonas chlororaphis O6 is differentially regulated by glucose", Lett. Appl. Microbiol., 52, pp. 532537 (2011). DOI: 10.1111/j.1472-765X.2011.03036.x

6. Kondratyuk, T.P., Park, E.J., Yu, R., Van Breemen, R.B., Asolkar, R.N., Murphy, B.T., Fenical, W., and
Pezzuto, J.M. "Novel marine phenazines as potential cancer chemopreventive and anti-inflammatory agents", Mar. Drugs., 10, pp. $451-464$ (2012). DOI: 10.3390/md10020451

7. Gilpin, M.L., Fulston, M., Payne, D., Cramp, R., and Hood, I. "Isolation and structure determination of two novel phenazines from a streptomyces with inhibitory activity against metallo-enzymes, including metallo$\beta$-lactamase", J. Antibiot., 48, pp. 1081-1085 (1995). DOI: 10.7164 /antibiotics.48.1081

8. Gebhardt, K., Schimana, J., Krastel, P., Dettner, K., Rheinheimer, J., Zeeck, A., and Fiedler, H.P. "Endophenazines A-D, new phenazine antibiotics from the Arthropod associated endosymbiont streptomyces anulatus", J. Antibiot., 55, pp. 794-800 (2002). DOI: 10.7164/antibiotics.55.794

9. Yun, B.S., Ryoo, I.J., Kim, W.G., Kim, J.P., Koshino, H., Seto, H., and Yoo, I.D. "Structures of phenazostatins A and B, neuronal cell protecting substances of microbial origin", Tetrahedron Lett., 37, pp. 8529-8530 (1996). DOI: 10.1016/0040-4039(96)01983-1

10. Laursen, J.B. and Nielsen, J. "Phenazine natural products: biosynthesis, synthetic analogues, and biological activity", Chem. Rev., 104, pp. 1663-1685 (2004). DOI: $10.1021 / \mathrm{cr} 020473 \mathrm{j}$

11. Khurana, J.M., Chaudhary, A., Lumb, A., and Nand, B. "An expedient four-component domino protocol for the synthesis of novel benzo [a] phenazine annulated heterocycles and their photophysical studie", Green. Chem., 14, pp. 2321-2327 (2012). DOI: 10.1039/C2GC35644A

12. Saluja, P., Chaudhary, A., and Khurana, J.M. "Synthesis of novel fluorescent benzo [a] pyrano [2, 3-c] phenazine and benzo [a] chromeno $[2,3-\mathrm{c}]$ phenazine 
derivatives via facile four-component domino protocol", Tetrahedron Lett., 55, pp. 3431-3435 (2014). DOI: $10.1016 /$ j.tetlet.2014.04.072

13. Hasaninejad, A. and Firoozi, S. "One-pot, sequential four-component synthesis of benzo[c]pyrano[3,2a]phenazine, bis-benzo[c]pyrano[3,2-a]phenazine and oxospiro benzo $[c]$ pyrano[3,2-a]phenazine derivatives using 1,4-diazabicyclo[2.2.2] octane (DABCO) as an efficient and reusable solid base catalyst", Mol. Diversity, 17, pp. 499-513 (2013). DOI: 10.1007/s11030-0139446-x

14. Mahdavinia, G.H., Mirzazadeh, M., and Notash, B. "A rapid and simple diversity-oriented synthesis of novel 3-amino- $2^{\prime}$-oxospiro [benzo[c]pyrano[3,2a]phenazine-1,3'-indoline]-2-carbonitrile/carboxylate derivatives via a one-pot, four-component domino reaction", Tetrahedron Lett., 54, pp. 3487-3492 (2013). DOI: $10.1016 /$ j.tetlet.2013.04.082

15. Bharti, R. and Parvin, T. "Multicomponent synthesis of diverse pyrano-fused benzophenazines using bifunctional thiourea-based organocatalyst in aqueous medium", Mol. Divers, 20, pp. 867-876 (2016). DOI: $10.1007 / \mathrm{s} 11030-016-9681-\mathrm{z}$

16. Abadi, A.Y.E., Maghsoodlou, M.T., Heydari, R., and Mohebat, R. "An efficient four-component domino protocol for the rapid and green synthesis of functionalized benzo[ $a]$ pyrano[2,3-c]phenazine derivatives using caffeine as a homogeneous catalyst", Res. Chem. Intermed., 42, pp. 1227-1235 (2016). DOI: 10.1007/s11164-015-2083-5

17. Yazdani-Elah-Abadi, A., Mohebat, R., and Maghsoodlou, M.T. "Theophylline as the catalyst for the diastereoselective synthesis of trans-1,2dihydrobenzo[ $[a]$ furo[2,3-c]phenazines in water", RSC. Adv., 6, pp. 84326-8433 (2016). DOI: 10.1039/C6RA18750A

18. Yazdani-Elah-Abadi, A., Mohebat, R. and Kangani, M. "Microwave-assisted and L-proline catalysed domino cyclisation in an aqueous medium: a rapid, highly efficient and green synthesis of benzo [a] phenazine annulated", J. Chem. Res., 40, pp. 722-726 (2016). DOI: 10.3184/174751916X14787124908891

19. Shaterian, H.R. and Mohammadnia, M. "Mild basic ionic liquid catalyzed four component synthesis of functionalized benzo [a] pyrano [2, 3-c] phenazine derivatives", J. Mol. Liq., 177, pp. 162-166 (2013). DOI: $10.1016 /$ j.molliq.2012.11.006

20. Shaabani, A., Ghadari, R., and Arabieh, M. "Synthesis of a new library of pyrano-phenazine derivatives via a novel three-component protocol", Helv. Chim. Acta, 97, pp. 228-236 (2014). DOI: 10.1002/hlca.201300006

21. Mohebat, R., Yazdani-Elah-Abadi, A., and Maghsoodlou, M.T. "A rapid and efficient domino protocol for the synthesis of functionalized benzo [a] pyrano [2, 3c] phenazine and benzo [f] pyrano [2, 3-h] quinoxaline derivatives", Res. Chem. Intermed., 42, pp. 6039-6048 (2016). DOI: $10.1007 / \mathrm{s} 11164-016-2437-7$
22. Mohebat, R., Yazdani-Elah-Abadi, A., Maghsoodlou, M.T., Mohammadi, M., and Heydari, R. "A green and efficient four-component sequential protocol for the synthesis of novel 16-(aryl)benzo[a]indeno $\left[2^{\prime}, 1^{\prime}: 5,6\right]$ pyrano[2,3-c] phenazin-15(16H)-one derivatives using oxalic acid as a reusable and cost-effective organic catalyst", Res. Chem. Intermed., 42, pp. 71217132 (2016). DOI: $10.1007 / \mathrm{s} 11164-016-2522-\mathrm{y}$

23. Gao, Y., Tang, P., Zhou, H., Zhang, W., Yang, H., Yan, N., Hu, G., Mei, D., Wang, J., and Ma, D. "Graphene oxide catalyzed $\mathrm{C}-\mathrm{H}$ bond activation: The importance of oxygen functional groups for biaryl construction", Angew. Chem. Int. Ed., 55, pp. 31243128 (2016). DOI: 10.1002/anie.201510081

24. Khodabakhshi, S., Marahel, F., Rashidi, A. and Abbasabadi, M.K. "A green synthesis of substituted coumarins using nano graphene oxide as recyclable catalyst", J. Chin. Chem. Soc., 62, pp. 389-392 (2015). DOI: $10.1002 /$ jccs. 201400349

25. Gao, L., Guest, J.R., and Guisinger, N.P. "Epitaxial graphene on $\mathrm{Cu}(111)$ ", Nano Lett., 10, pp. 3512-3516 (2010). DOI: $10.1021 / \mathrm{nl} 1016706$

26. Stankovich, S., Dikin, D.A., Piner, R.D., Kohlhaas, K.A., Kleinhammes, A., Jia, Y., Wu, Y., Nguyen, S.T., and Ruoff, R.S. "Synthesis of graphenebased nanosheets via chemical reduction of exfoliated graphite oxide", Carbon, 45, pp. 1558-1565 (2007). DOI: $10.1016 /$ j.carbon.2007.02.034

27. Mohanty, N. and Berry, V. "Graphene-based singlebacterium resolution biodevice and DNA transistor: interfacing graphene derivatives with nanoscale and microscale biocomponents", Nano Lett., 8, pp. 44694476 (2008). DOI: $10.1021 / \mathrm{nl} 802412 \mathrm{n}$

28. Mazloum-Ardakani, M., Farbod, F., and Hosseinzadeh, L. "Enhanced electro-oxidation of urea based on nickel nanoparticle decorated reduced grapheme oxide/PEDOT:PSS composite", Scientia Iranica, Trans. F., 24, pp. 1678-1685 (2017). DOI: $10.24200 /$ sci.2017.4144

29. Sadeghzadeh, S. "Impact dynamics of graphene nanosheets in collision with metallic nanoparticles", Scientia Iranica, Trans. F., 23, pp. 3153-3162 (2016). DOI: $10.24200 /$ sci.2016.4020

30. Stankovich, S., Piner, R., Nguyen, S.T., and Ruoff, R.S. "Synthesis and exfoliation of isocyanate-treated graphene oxide nanoplatelets", Carbon, 44, pp. 33423347 (2006). DOI: 10.1016/j.carbon.2006.06.004

31. Lu, C.H., Yang, H.H., Zhu, C.L., Chen, X., and Chen, G.N. "A graphene platform for sensing biomolecules", Angew. Chem., Int. Ed., 48, pp. 4785-4787 (2009). DOI: 0.1002/anie.200901479

32. Hummers, W.S. and Offeman, R.E. "Preparation of graphitic oxide", J. Am. Chem. Soc., 80, pp. 13391339 (1958). DOI: $10.1021 /$ ja01539a017

33. Tien, H.N., Luan, V.H., Lee, T.K., Kong, B.S., Chung, J.S., Kim, E.J., and Hur, S.H. "Enhanced solvothermal reduction of graphene oxide in a mixed solution of 
sulfuric acid and organic solvent", Chem. Eng. J., 211, pp. 97-103 (2012). DOI: 10.1016/j.cej.2012.09.046

34. Wang, S.L., Wu, F.Y., Cheng, C., Zhang, G., Liu, Y.P., Jiang, B., Shi, F., and Tu, S.J. "Multicomponent synthesis of poly-substituted benzo[a]pyrano[2,3c]phenazine derivatives under microwave heating", ACS Comb. Sci., 13, pp. 135-139 (2011). DOI: $10.1021 / \operatorname{co} 1000376$

\section{Biographies}

Javad Safaei-Ghomi received a BS degree in Chemistry from the University of Kashan, Iran, in 1985; an MS degree in Organic Chemistry from the University of Mazandaran, Babolsar, Iran, in 1988; and a PhD degree in Organic Chemistry from the University of Wollongong, Australia, in 1995. $\mathrm{He}$ is currently professor in the Department of Organic Chemistry at the University of Kashan, Iran. His research interests include asymmetric synthesis of amino acids, antioxidant and antibacterial activity of herbal extracts, using nanoparticles in multicomponent reactions, and new methods for functionalization of fullerene.

Maryam Tavazo received BS and MS degrees in Chemistry from the University of Marvdasht, Iran. Also, she received the $\mathrm{PhD}$ degree under the supervision of Professor Javad Safaei-Ghomi from the University of Kashan, Iran. Her research interests include using nanoparticles in multicomponent reactions and new methods for functionalization of nanocatalysts.

Hossein Shahbazi-Alavi obtained his MS degree in Organic Chemistry from the University of Kashan, Iran, in 2013, on the study of synthesis of phthalazine derivatives under solvent-free conditions. He also received his $\mathrm{PhD}$ degree under the supervision of Professor Javad Safaei-Ghomi from the same university. 